\title{
Facilitação Neuromuscular Proprioceptiva em tatame na reaquisição de funçóes na lesão medular
}

\author{
Neuromuscular Facilitation Proprioceptive on the mat repurchase of functions in spinal cord injury
}

Roselene Ferreira de Alencar', Tatiane Guedes Ferreira Cordeiro ${ }^{2}$, Patricia
Geysiane S dos Anjos ${ }^{3}$, Poliana L Cavalcanti

\section{RESUMO}

\begin{abstract}
A lesão raquimedular é uma das formas mais graves entre as lesões incapacitantes. Quando um indivíduo sofre tal lesão ocorre interferência da transmissão dos impulsos nervosos motores e sensoriais, além de modificaçôes autonômicas gerando intenso conflito econômico e social para o paciente, família e sociedade. É essencial que se estabeleça um tratamento fisioterapêutico adequado proporcionando reaprendizado como também retorno as atividades funcionais anteriormente realizadas importantes para as atividades de vida diária. A Facilitação Neuromuscular Proprioceptiva (FNP) tem o objetivo primário de facilitar o paciente a alcançar o mais alto nível funcional reforçando e utilizando o que ele pode fazer. Este relato de caso é de caráter exploratório e descritivo com o objetivo de mensurar os efeitos da aplicação da FNP em atividades de tatame na reaquisição de padróes motores normais em um paciente com lesão medular traumática acompanhado no centro universitário de João Pessoa. Constatou-se que a FNP contribuiu para o processo de aprendizagem motora neste paciente, favorecendo a reaquisição dos padrōes motores, e proporcionando maior independência e qualidade de vida.
\end{abstract}

Unitermos. Traumatismos da medula espinal, Reabilitação, Modalidades de Fisioterapia.

Citaçáo. Alencar RF, Cordeiro TGF, Anjos PGS, Cavalcanti PL. Facilitação Neuromuscular Proprioceptiva em tatame na reaquisição de funçôes na lesão medular.

\begin{abstract}
The spinal cord injury is one of the most serious between the disabling injuries. When an individual suffers damage as interference is the transmission of nerve impulses and sensory motor, and autonomic changes generating intense economic and social conflict for the patient, family and society. It is essential to establish an appropriate physical therapy treatment as well as providing learning return to functional activities previously undertaken important for activities of daily living. The proprioceptive neuromuscular facilitation (PNF) has the primary objective of facilitating the patient to achieve the highest level functional strengthening and using what he can do. This case report is exploratory and descriptive in nature with the purpose of measuring the effects of the activities of the PNF in tatamis in reacquisition of normal motor patterns in a patient with traumatic spinal cord injury center at the University of together in João Pessoa. It was found that the PNF contributed to the process of motor learning in this patient, encouraging the purchase of motor patterns, and providing greater independence and quality of life.
\end{abstract}

Keywords. Spinal cord injuries, Rehabilitation, Physical Therapy Modalities.

Citation. Alencar RF, Cordeiro TGF, Anjos PGS, Cavalcanti PL. Neuromuscular Facilitation Proprioceptive on the mat repurchase of functions in spinal cord injury.

\footnotetext{
Trabalho realizado na clínica de Fisioterapia do UNIPE, Joáo Pessoa-PB, Brasil.

1. Fisioterapêuta, mestre, professora da UFRN, UNIPE/PB e da Asper-PB, João Pessoa-PB, Brasil.

2. Fisioterapêuta, Pós-graduada pela Faculdade Redentor-PE e pela FIP-PB e professora da FIP, Patos-PB, Brasil.

3. Fisioterapeuta graduada pelo UNIPE/PB; Pós-graduanda em fisioterapia

Cardiorrespiratória- Fac, Redentor, Recife-PE, Brasil.

4. Fisioterapeuta graduada pelo UNIPE/PB; Pós-graduanda em fisioterapia

Cardiorrespiratória- Fac, Redentor, Recife-PE, Brasil.
}

Endereço para correspondência: Tatiane GF Cordeiro Rua Major Salustino Ribeiro, no 189b, Tambauzinho CEP 58042-090, João Pessoa-PB, Brasil. Fone: (83) 8812.3666 E-mail: tianeguedes@hotmail.com

Relato de Caso Recebido em: 07/05/10 Aceito em: 19/11/10 Conflito de interesses: nẫo 


\section{INTRODUÇÃO}

A cada ano no Brasil e no mundo surgem muitos novos casos de lesão medular que resultam em comprometimento funcional. Tornam-se então importante um reaprendizado e treinamento destes pacientes para o retorno das atividades táo corriqueiramente realizadas e agora tão difíceis de serem realizadas. Levando em consideração que o movimento humano é feito por combinaçóes de movimentos e não num único plano, foram escolhidas para este estudo as técnicas de FNP, visto que um de seus objetivos é direcionado para adquirir funções através dos movimentos tridimensionais como rolar, sentar, elevar tronco superior, ajoelhar, engatinhar, semiajoelhar, assumir bipedestação e deambular. $\mathrm{O}$ método trabalha com diversas funções como irradiação de forca, fortalecimento muscular, aumento do controle motor, entre outros. Será enfatizado na pesquisa o uso das diagonais nas atividades de colchão ${ }^{1}$.

Inicialmente o Dr. Herman Kabat, na década de 40, começou com o termo "facilitação proprioceptiva". Em 1954, Dorothy Voss adicionou a palavra "neuromuscular" para formar a expressão Facilitação Neuromuscular Proprioceptiva (FNP). O conceito do Dr. Kabat para FNP surgiu de sua experiência como neurofisiologista e médico. Seu objetivo era desenvolver um método de tratamento que empregasse resistência manual que permitisse aos clínicos analisar e avaliar os movimentos do paciente e que ao mesmo tempo facilitasse estratégias mais eficientes de movimentos funcionais. Por isso que A FNP não é apenas um método de tratamento, mas sim uma ferramenta que permite ao mesmo tempo avaliação e tratamento de disfunções neuromusculares. A FNP também inclui aprendizado motor e retenção funcional de atividades recém-aprendidas por meio da repetição de uma demanda específica; a utilização do desenvolvimento do comportamento motor que permite aos pacientes criar e recriar estratégias de movimentos funcionais eficientes e a análise biomecânica e comportamental do controle motor. Todas as atividades dentro das intervençôes com FNP são orientadas para um objetivo funcional e são relativas ao ambiente no qual o objetivo a ser alcançado está inserido ${ }^{2,3}$.

As técnicas de facilitação neuromuscular proprioceptiva se propóem a auxiliar o indivíduo no processo de reabilitação ou na melhora de sua condição física, exigin- do do paciente maior aprendizagem motora e performance, flexibilidade e aumento da amplitude de movimento, fortalecimento muscular e coordenaçáo motora. Com o uso da neurofisiologia aliado aos padróes de movimentos em massa que compóem o Método Kabat, de caráter espiral e diagonal, baseados num profundo estudo anatômico e biomecânico, que se assemelham muito aos movimentos empregados no esporte e atividades de vida diária e no trabalho é possível resolver desde alteraçôes neuromusculares até melhorar condição física para atividades desportivas ${ }^{4-6}$.

Aprendizado motor é o processo pelo qual o sistema nervoso modifica suas respostas motoras. Sendo um processo implícito, tem como principais características o desenvolvimento lento, baseado em um grande número de repetiçóes, cujos resultados só podem ser verificados através da modificação no desempenho. Os modelos atuais de aprendizado motor consideram a realimentação sensorial fundamental para o processo à medida que permite, com base nas informaçóes sensoriais resultantes da repetição anterior, o aperfeiçoamento da próxima tentativa. A FNP têm utilizado a realimentação sensorial como uma importante ferramenta para melhorar o desempenho motor de pacientes com disfunçôes neurológicas ${ }^{5,7,8}$.

O objetivo desta pesquisa foi verificar a aplicação do método na reaquisição das capacidades para realizar as atividades funcionais com maior independência e para isso é preciso identificar o nível de função do paciente; aplicar o método enfatizando as atividades que foram perdidas ou prejudicadas neste paciente; demonstrar os benefícios encontrados com a aplicação do método de facilitação.

\section{MÉTODO}

Trata-se de um relato de caso de um paciente de 18 anos, sexo masculino, com diagnóstico de lesão medular cervical incompleta ao nível de C3-C4 que apresenta déficits motores e sensoriais. Tem caráter exploratório e descritivo, com a técnica de documentaçáo indireta e direta devido ao emprego da observação intensiva e direta do paciente assim como outros instrumentos que serão aludidos posteriormente.

A FNP foi a única técnica e conduta de escolha para conduzir o processo de reabilitaçáo do paciente. 
As aplicações do método foram realizadas por um único profissional fisioterapeuta em duas sessóes semanais com duração de cinquenta minutos, totalizando vinte e oito atendimentos, em torno de seis meses, incluindo as avaliaçóes, nas dependências do Centro Universitário de João Pessoa - UNIPE localizado na BR 230 - Km 22, João Pessoa - Paraíba, visto oferecer condições adequadas para sua realização.

Os procedimentos da coleta de dados foram rigorosos afim de garantir a confiabilidade dos resultados obtidos. São eles: observação in loco e espontânea do paciente durante a aplicação do método; máquina fotográfica digital; diário de campo e depoimentos pessoais de atividades relatadas pelo paciente em domicílio; ficha de avaliação fisioterapêutica neurológica; ficha específica de avaliação do controle motor adaptada ${ }^{3,9}$.

A avaliação funcional é a determinação das habilidades motoras e realizou-se através de uma ficha de avaliação das habilidades motoras elaborada pela autora sendo aplicada em três períodos: a primeira análise antes da intervenção fisioterapêutica, a segunda após sete atendimentos e também período de recesso do UNIPE e a terceira após dezoito atendimentos ${ }^{3,10}$. Posteriormente foi feita uma análise qualitativa com interpretação dos dados coletados.

A realização deste estudo considerarou a Resolução no 196/96 do Conselho Nacional de Saúde que rege sobre a ética da pesquisa envolvendo seres humanos direta ou indiretamente, assegurando a garantia de que a privacidade do sujeito da pesquisa será preservada (BRASIL-MS, 1996). Foi submetido ao Comitê de Ética em Pesquisa. Após a concessão de sua aprovação, o sujeito envolvido na pesquisa foi informado sobre todos os procedimentos necessários para o estudo e assinou o termo de consentimento livre e esclarecido (TCLE), impresso em duas vias, uma para o pesquisado e outra para o pesquisador.

Durante o transcorrer da pesquisa, foi indispensável o cuidado com as observâncias éticas, preconizadas para a pesquisa envolvendo seres humanos, de acordo com a Resolução supracitada. Nesse sentido, todas as informaçôes guardadas de forma sigilosa.

\section{RESULTADOS E DISCUSSÃO}

$\mathrm{Na}$ primeira avaliação o paciente fazia uso de ca- deira de rodas e era dependente com assistência elevada para banhos, asseios e transferências na cama, cadeira de rodas e banheiro, dependência com assistência moderada para alimentação, como também para vestir parte inferior do corpo, e déficits nos controle vesical e de esfíncter anal além de dependência com assistência mínima para vestir a parte superior do corpo

Ao final, durante a avaliação, observou-se que deambulava com apoio de muletas canadenses para grandes distâncias e sem apoio para pequenas distâncias, porém com dificuldades, realizando flexão lateral do tronco para direita, déficit em flexão de joelho e tornozelo direito e pouca transferência de peso para o dimídio direito e independência com segurança para todas as atividades de vida diária (AVD's) supracitadas.

$\mathrm{Na}$ primeira avaliação funcional detectou-se a execução das atividades como rolar de ventral para dorsal e vice-versa com dificuldades, dissociação de tronco em decúbito lateral (DL) com limitação ao uso de resistência adequada, elevação de tronco inferior sem uso de resistência e esboço das atividades de elevação de tronco superior e sentar a partir de decúbito dorsal (DD). As demais avaliaçóes comparando os ganhos funcionais podem ser melhor visualizadas no Quadro 1.

As evoluçóes dos padrões motores adquiridos são detalhadamente descritas a seguir durante a aplicação da Facilitação Neuromuscular Proprioceptiva no tatame.

As atividades motoras em tatame utilizando a FNP e direcionadas ao paciente em questão buscaram a obtenção de ganhos funcionais onde o ato de rolar proporciona independência nas mudanças de postura e de decúbito, o sentar auxilia nas AVD's e as posturas de gato e ajoelhado facilitam o treino de marcha posterior. As atividades foram realizadas sem o uso de lençol ${ }^{11-13}$.

Antes de cada atendimento foi realizado alongamentos valorizando os movimentos em espiral e nas diagonais do método de Facilitação Neuromuscular Proprioceptiva, que são mais eficazes e funcionais ${ }^{12}$. Utilizou-se os seguintes alongamentos:

**Alongamento tronco com os padróes associados de ântero-elevação da escápula com póstero-depressão da pelve e também póstero-depressão da escápula com ântero-depressão da pelve nos lados direito e esquerdo do corpo, onde o paciente só conseguiu realizar com o membro 
Habilidades motoras adquiridas

\begin{tabular}{|c|c|c|c|c|}
\hline \multicolumn{2}{|c|}{ Posturas e padróes gerais } & \multirow{2}{*}{$\frac{1^{\text {a }} \text { avaliaçáo }}{W}$} & \multirow{2}{*}{$\frac{2^{\mathbf{a}} \text { avaliaçáo }}{\mathrm{M}}$} & \multirow{2}{*}{$\frac{3^{\mathbf{a}} \text { avaliaçáo }}{M}$} \\
\hline Rolar & Ventral para dorsal & & & \\
\hline & Dorsal para ventral & W & M & M \\
\hline Dissociação de tronco & Em DL & $\mathrm{N}$ & M & M \\
\hline Tronco inferior & Elevação & $\mathrm{P}$ & M & M \\
\hline \multirow[t]{6}{*}{ Progressão Ventral } & Sobre cotovelos & I & M & M \\
\hline & Eleva tronco superior & I & M & M \\
\hline & Arrastar-se & $\mathrm{F}$ & $\mathrm{N}$ & M \\
\hline & Apoio sobre cotovelo e joelhos & $\mathrm{F}$ & M & M \\
\hline & Gatinho & $\mathrm{F}$ & M & M \\
\hline & Engatinhar & $\mathrm{F}$ & M & M \\
\hline \multirow[t]{3}{*}{ Erguer e sentar } & Sentar de lado (DD para DV) & $\mathrm{F}$ & W & W \\
\hline & $\begin{array}{c}\text { Sentar com MMII estendidos a } \\
\text { partir de DD }\end{array}$ & I & $\mathrm{N}$ & M \\
\hline & Sentar em cadeira & $\mathrm{F}$ & $\mathrm{P}$ & $\mathrm{N}$ \\
\hline \multirow[t]{2}{*}{ Erguer de joelho } & Sentado sobre calcanhar & F & W & $\mathrm{N}$ \\
\hline & De quatro (gatinho) & $\mathrm{F}$ & M & M \\
\hline $\begin{array}{l}\text { De gatinho para } \\
\text { semiajoelhado }\end{array}$ & & $\mathrm{F}$ & M & M \\
\hline \multirow[t]{3}{*}{ Erguer-se de pé } & Planta dos pés (plantígrado) & $\mathrm{F}$ & $\mathrm{F}$ & $\mathrm{F}$ \\
\hline & Semi ajoelhado & $\mathrm{F}$ & W & M \\
\hline & Sentado em cadeira & $\mathrm{F}$ & $\mathrm{P}$ & M \\
\hline \multirow[t]{3}{*}{ Andar } & Nível & $\mathrm{F}$ & $\mathrm{F}$ & M \\
\hline & Rampa & F & $\mathrm{F}$ & W \\
\hline & Escada & $\mathrm{F}$ & $\mathrm{F}$ & W \\
\hline Correr, saltar, pular & & $\mathrm{F}$ & $\mathrm{F}$ & $\mathrm{F}$ \\
\hline
\end{tabular}

( $\mathrm{M}$ = padráo é executado de maneira coordenada, ativamente com força adequada, contra resistência; $\mathrm{N}$ = Resposta voluntária com nível de controle normal, porem limitado com uso de resistência adequada; $\mathrm{P}=$ Resposta voluntária com nível de controle normal ou presente, sem resistência; $\mathrm{W}$ = A resposta voluntária é presente, mas fraca ou a amplitude de movimento é limitada; I = Inicia o movimento (esboço); $\mathrm{F}=$ Ausência de resposta voluntária, mas a resposta pode ser facilitada).

inferior direito (MID) EM PADRÃO DE EXTENSÃO devido À hipertonia;

**Alongamento dos membros superiores (MMSS) em diagonal funcional com flexão, adução e rotação externa (VADD @ EXT) padrão original e seu antagonista EXTENSÃO, abdução e rotação interna (/ ABD @ INT) padrão original e em diagonal primitiva com flexão, abdução e rotação externa (V ABD @ EXT) em padrão original e com variante de $\mathrm{V}$ de cotovelo melhorando a rigidez extensora principalmente em membro superior direito (MSD) e seu antagonista nos padróes originais.
** Alongamento dos membros inferiores (MMII) em diagonal funcional de V ADD @ EXT sendo o padrão original e com variante de $\mathrm{V}$ de joelho REDUZINDO a rigidez extensora principalmente de membro inferior direito (MID) e seu padrão antagonista original, além da diagonal primitiva de V ADD @ INT original e com V de joelho e seu padrão antagonista.

Foi iniciada a conduta proposta com a FNP sendo realizado o treino do rolar de DD para decúbito ventral (DV) tanto para direita quanto para esquerda, com o padrão extensão, abdução e rotação interna (/ ABD @ 
INT) de membro inferior direito (MID) com variante de / de joelho, com contato proximal em borda externa e posterior da coxa, logo acima da articulaçáo do joelho e contato distal apoiando a planta do pé na sua face interna, e através do comando "empurre seu pé, gire a cabeça e olhe para cima e role". Explanou-se ao paciente que tal movimento deve ser realizado associado aos padróes de I @ do pescoço para o lado do rolar e flexão, adução e rotação externa (V ADD @ EXT) do membro superior (MS) livre ${ }^{12}$.

Posteriormente foi iniciado o treino de elevar sobre os antebraços e mãos através do padrão da FNP com os movimentos combinados de extensão e rotação (/ @) do pescoço resistido com os contatos manuais sendo a superfície palmar lateral da mão e dedos na regiáo inferior da mandíbula e superfície palmar lateral da outra mão e dedos na região lateral do crânio sob o comando "gire a cabeça, olhe para mim e eleve" (Figura 1). É importante ressaltar que o paciente é informado antes de cada atividade através do comando de preparação ${ }^{12}$.
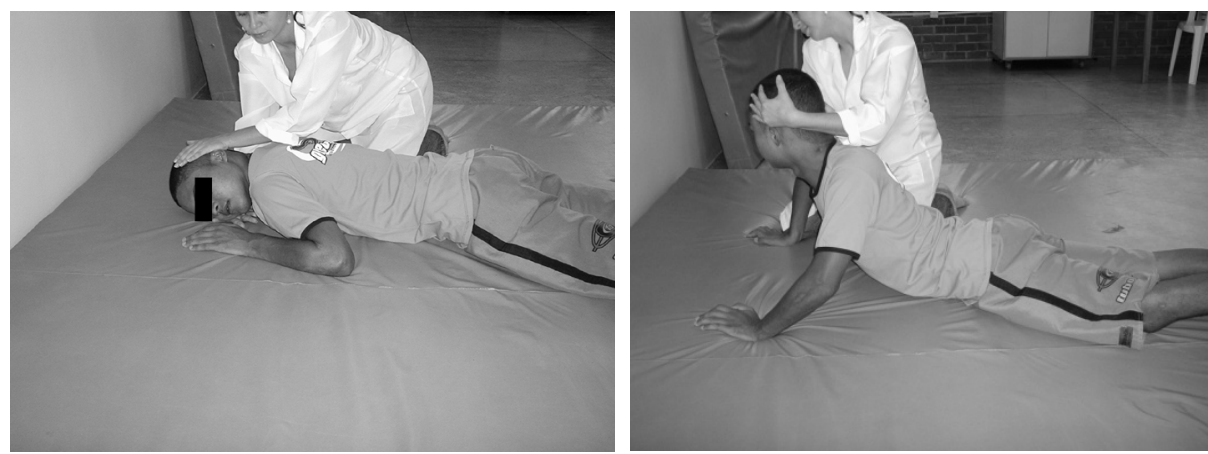

Figura 1. Elevação de tronco com extensão de MMSS.

Treinou-se também o sentar com os membros inferiores (MMII) estendidos a partir do DD através do padrão de flexão e rotação $(\mathrm{V} @)$ de tronco superior em que o MS guia, faz extensão, abdução e rotação interna (/ ABD @ INT), o outro MS apoia no antebraço contralateral realizando extensão, adução e rotação interna (/ ADD @ INT) e o pescoço, flexão e rotação (V @) para o lado da rotaçáo fletindo o tronco anteriormente. Os contatos manuais foram no dorso da mão do membro guia do paciente e no lado temporal do crânio. Devido às dificuldades do paciente em realizar a atividade solicitada observou-se a necessidade de adaptação, não apoiando o
MS no antebraço oposto. O comando verbal requerido "estique os dedos e a mão, gire o polegar, força com o braço para baixo e para mim, olhe para sua mão e sente"3.

Em sequência foi iniciada a postura sobre cotovelos e joelhos, ou "gatinho", através do padrão resistido de póstero-depressão da pelve com flexão e rotação (V @) do pescoço livre sob o comando verbal "empurre minha mão levante a pelve e erga em minha direção e fique de gatinho" 12 .

Adicionou-se ao tratamento a execução da postura sentada sobre os calcanhares a partir de apoio sobre os cotovelos e joelhos com o padrão de flexão e rotação (V@) pescoço solicitado pelo comando verbal "encoste o queixo no peito, olhe para pelve oposta e sente sobre os calcanhares" $"$.

$\mathrm{Na}$ postura citada acima, foram trabalhadas técnicas específicas, todas transferindo o peso para frente $\mathrm{e}$ para trás, descritas por Lucetti e Moreira ${ }^{12}$ como:

** Reversão dos antagonistas: técnica iniciada pelo padrão mais forte da diagonal de movimento, incluindo os procedimentos básicos com contraçóes isotônicas e ao alcançar a amplitude máxima, muda-se os contatos manuais para executar o padrão antagonista, sem permitir o relaxamento e excluindo os procedimentos de tração, aproximação e reflexo de estiramento entre um padrão e outro.

** Contraçóes repetidas verdadeiras: o padrão é iniciado com todos os procedimentos básicos, requerendo contração isotônica. Ao chegar ao momento mais forte do padrão solicita-se contração isométrica apontando para os componentes rotatórios, e, quando obtida estabilização, solicita-se contração isotônica associada aos reflexos de estiramento, intercalados até o final do padrão, exceto logo após a contração isométrica.

** Estabilização rítmica: É escolhido o padrão forte do movimento e realizada a contraçáo isométrica dos grupos musculares agonistas e antagonistas, com mudança dos contatos manuais e ressaltando o componente rotatório do padrão sem relaxamento entre as contrações. 
Em seguida efetuamos a postura ajoelhada a partir de sentado sobre calcanhares na pelve com resistência adequada e depois aproximação estimulando os receptores articulares com o comando "empurre minha mão e fique de joelho". O paciente alcança tal atividade com dificuldades, contudo foi iniciada a técnica de estabilização rítmica ${ }^{3}$.

Atingiu-se a atividade por meio do padrão flexão, abdução e rotação interna (V ABD @ INT) do membro inferior (MI) com o contato proximal na face antero-lateral logo acima do joelho e distal no dorso do pé, apoiando-o assim no colchão com o comando verbal "leve a perna para frente, cobre o joelho e apoie o pé no chão”. E nesta postura o paciente permaneceu sozinho apenas por pouco tempo devido fraqueza nos MMII e hipertonia de adutores ${ }^{12}$.

Foi exercitada na postura ajoelhada a técnica estabilização rítmica com os padrões bilaterais simétricos antagonistas associando póstero-elevação com ânterodepressão das escápulas e póstero-depressão com ânteroelevação, reversão dos antagonistas, com contato manual na pelve e também com a combinação pelve-escápulapescoço realizando ântero-elevação da pelve, póstero-depressão da escápula oposta e extensão e rotação (/ @) do pescoço estendendo o tronco e seu padrão antagonista. Ainda ajoelhado, solicitou-se a "marcha" com e sem resistência na pelve com o estímulo de estiramento e aproxi- mação sob o comando verbal "leve a perna para frente"12.

Enfatizou-se a passagem da postura semiajoelhada para bípede com o auxílio da Barra de Ling com o contato manual pélvico e aproximação ao adquirir a bipedestação. Onde o paciente mostrou dificuldades ao cumprir a atividade devido déficit de força nos MMII, principalmente MID executando com mais habilidade quando o MIE está à frente com o pé apoiado no chão (Figura 2) ${ }^{14}$.

Em bipedestação foram trabalhadas contrações repetidas verdadeiras e estabilização rítmica nos movimentos bilaterais simétricos antagonistas de ântero-elevação com póstero-depressão tanto da pelve como da escápula com a resistência aplicada adequadamente e suporte de peso de um lado para outro, para frente e para trás com base ampla e o passo repetido. Acrescentou-se a marcha lateral com auxílio da Barra de Ling e contato manual na pelve, sendo executado com bastante dificuldade, principalmente para o dimídio direito devido MID hipertônico ${ }^{12,15}$.

Foram acrescentadas às técnicas de contraçóes repetidas verdadeiras e estabilização rítmica com os padróes combinados de pelve, escápula e de pescoço livre, com contato manual na pelve e escápula combinando pelveescápula-pescoço realizando ântero-elevação da pelve, póstero-depressão da escápula oposta e extensão e rotação (/ @) do pescoço estendendo o tronco e seu padrão antagonista na postura bípede ${ }^{15}$.
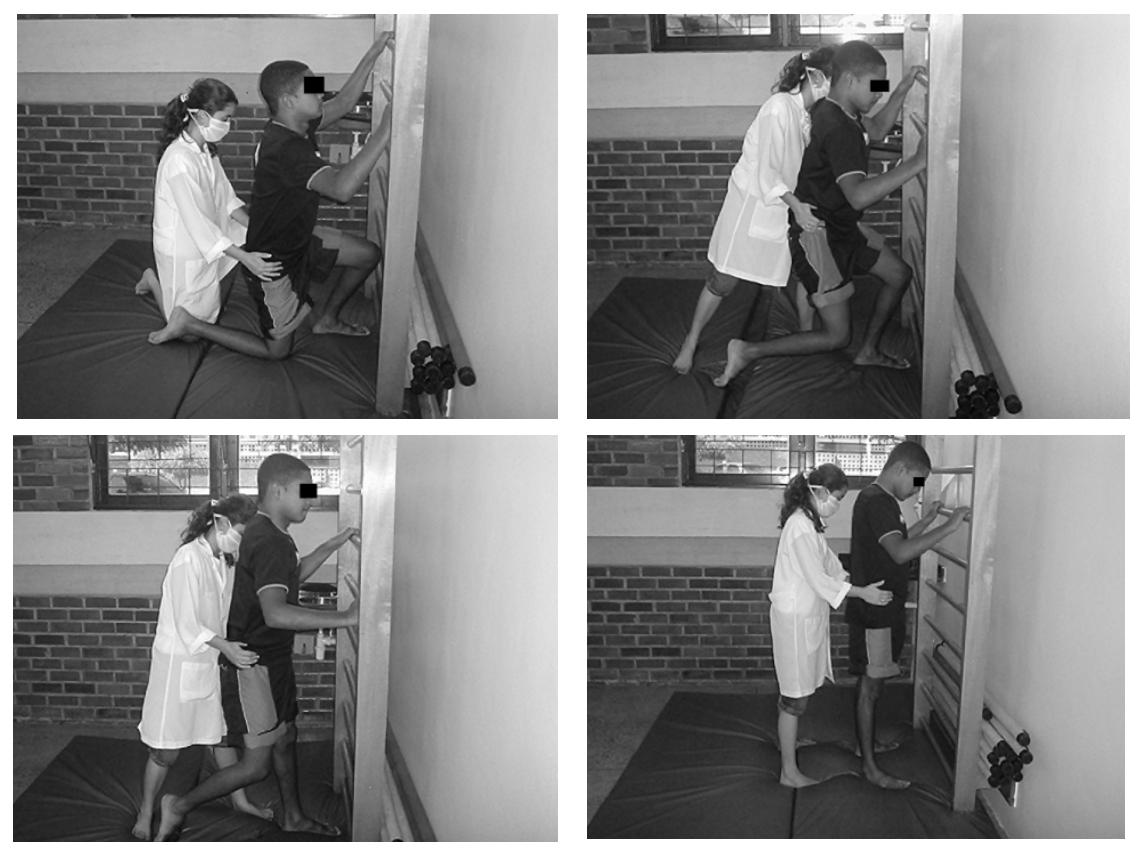

Figura 2. De semiajoelhado para postura bípede. 
Efetivou-se todas as atividades seguindo a se-quência: rolar de DD para DV e vice-versa, elevaçáo do tronco com MMSS, sentar a partir de DD, apoio sobre cotovelos e joelhos a partir de DV, e então sentar sobre calcanhares, deste para postura ajoelhada, marcha de joelhos, postura de gatinho a partir do apoio sobre cotovelos e joelhos, de gatinho para semiajoelhado, deste para postura bípede, adicionando também a postura bípede a partir de sedestação (cadeira), utilizando sempre padróes combinados de pelve, escápula, pescoço e membros, tanto ajoelhado como na bipedestação, marcha lateral e para frente, iniciadas nas barras paralelas e posteriormente muletas canadenses. Todas estas fases foram realizadas utilizando apenas o método da FNP com todos os procedimentos básicos específicos. À técnica, como reflexo de estiramento, padrôes de facilitação, resistência manual, posição corporal e biomecânica, irradiação e reforço, contato manual, comando verbal, tração e aproximação, estímulo visual e sincronização de movimentos.

Com toda a explanação acima pôde ser observado que a evolução do paciente foi bastante válida, visto ter sido registrado em tempo hábil a aquisição de novos padrôes motores passando pelos estágios do controle motor progressivamente até conseguir a habilidade dos padrôes através do aprendizado motor. Estas habilidades podem ser melhor comparadas no Quadro 1 onde cada letra representa um nível de resposta.

\section{CONSIDERAÇÕES FINAIS}

Mostra-se neste relato de caso que a FNP em tatame é eficaz na recuperação da função, sendo esta definida conforme O'Sullivan, Schmitz ${ }^{13}$ "a reaquisição das habilidades de movimento perdidas como conse-quência de lesão levando em consideração a plasticidade neural".

Observou-se significativa evolução do paciente constatada ao comparar as condiçóes deste na primeira avaliação e na avaliação final, em função da observação da aquisição dos padrốes motores anteriormente não conseguidos, desde o rolar até a bipedestação e principalmente a deambulação.

A importância do estudo traduz-se pela aplicação da FNP com o intuito de facilitar o processo de re- educação funcional e aquisição de habilidades motoras, proporcionando uma maior autonomia e independência do paciente com lesão medular, demonstrando ser uma possibilidade instrumento terapêutico no que se refere ao processo de reabilitação. Soma-se a este o estímulo para execução da técnica não apenas reportar um caso, mas utilizar com amostras randomizadas para, por conseguinte demonstrar a probabilidade de facilitar suas atividades diárias contribuindo para um bem estar e satisfação pessoal e benefícios sociais.

\section{REFERÊNCIAS}

1.Waddington PJ. Atividades Funcionais sobre Tablados. In: Flercher-Cook, P; Hollis, M. Exercícios Terapêuticos Práticos. Sáo Paulo: Santos, 2002, 323p. 2.Associação Internacinal PNF, Perspectivas Históricas da PNF (endereço na internet). Carsten Schärfer (última atualizaçáo: 29 de abril de 2009; citado em: 01 de agosto de 2009). Disponível em: http: www.ipnfa.org/index.php?id=113. 3.Ionta MK, Myers BJ, Voss DE. Facilitação Neuromuscular Proprioceptiva. Terceira Edição. São Paulo: Panamericana, 1987, 488p.

4.Prentice WE. Técnicas de facilitação neuromuscular proprioceptiva (FNP) em reabilitação. In: Prentice E, Voight ML. Técnicas em reabilitação Musculoesqueléticas. Porto Alegre: Artmed, 2003, 728p.

5.Barela JA. Aquisição de habilidades motoras: Do inexperiente ao habilidoso. Rev Motriz 1999;5:57-3.

6.Magill RA. Aprendizagem Motora: Conceito e aplicaçôes. São Paulo: Edgard Blucher, 2002, 273p.

7.Newton RA. Questôes e Teorias Atuais sobre Controle Motor: Avaliação de Movimento e Postura. In: Umphred, DA. Fisioterapia neurológica. São Paulo: Manole, 1994, 577p.

8.Pellegrini AM. A aprendizagem de habilidades motoras I: O que muda com a prática? Rev Paulista Educ Fís 2000;3:34-29.

9.Atrice MB, McDowell SL, Morrison SA, Shadalov B. Lesão Medular Traumática. In: Umphred DA. Fisioterapia neurológica. 2. ed. São Paulo: Manole, 2004, p577.

10.Schmitz TJ. Lesão Medular Traumática. In: O`Sullivan SB, Schmithz TJ. Fisioterapia Avaliação e tratamento. 2.ed. São Paulo: Manole, 1993, 671p.

11.Lianza S, Casalis MEP, Greve JMD, Eichberg R. A lesão medular. In: Lianza S. Medicina de reabilitaçấo. Rio de Janeiro: Guanabara Koogan; 2001, p.322. 12.Lucetti MSB, Moreira MFAP de. Facilitação Neuromuscular Proprioceptiva - Método Kabat (Curso), 2004 Jun- Dez. João Pessoa, Paraíba. Centralfisio, 2004.

13.O Sullivan SB, Schmitz TJ. Fisioterapia Avaliação e tratamento. Segunda Ediçẫo. São Paulo: Manole, 2007, 671p.

14. Reichel HS. Método Kabat Facilitação Neuromuscular Proprioceptiva. São Paulo: Premier, 1998, p.171.

15.Adler SS, Beckers DBM. PNF Facilitação Neuromuscular Proprioceptiva. São Paulo: Manole, 1999, p.290. 